DOI: http://dx.doi.org/10.18203/2319-2003.ijbcp20203631

\title{
Evaluation of adverse drug reactions of anti-tubercular drugs in the treatment of tuberculosis in tertiary care hospital
}

\author{
Krishnakanth K., Jagadeesh A.*, Swetha T. D. \\ Department of Pharmacology, NRI Medical College and Hospital, Chinakakani, Guntur, Andhra Pradesh, India
}

Received: 02 August 2020

Revised: 17 August 2020

Accepted: 18 August 2020

*Correspondence:

Mr. Jagadeesh A.,

Email: jagannri@gmail.com

Copyright: ( $)$ the author(s), publisher and licensee Medip Academy. This is an open-access article distributed under the terms of the Creative Commons Attribution Non-Commercial License, which permits unrestricted non-commercial use, distribution, and reproduction in any medium, provided the original work is properly cited.

\begin{abstract}
Background: Adverse drug reactions are very common among patients on anti-tubercular treatment. Hence, the current study was done to evaluate the adverse drug reaction (ADR) profile in patients receiving anti-tubercular treatment (ATT).

Methods: A 6 months prospective, cross-sectional observational study was performed in collaboration with Pulmonology Medicine department. WHO-UMC scale and Naranjo scale was used to evaluate the ADRs.

Results: Ninety-two patients receiving ATT presented with 113 adverse drug events (ADE). Males were more affected than females. DOTS category-1 regimen was mostly responsible for ADE. Addition of drugs for the management of ADR events was done.

Conclusions: The study results show more ADRs related to ATT demanding increased collaboration between NTEP 2020 and Pharmacovigilance Programme of India to enhance drug safety in this field.
\end{abstract}

Keywords: Tuberculosis, Naranjo scale, WHO-UMC scale

\section{INTRODUCTION}

National tuberculosis elimination programme (NTEP) 2020 was introduced by government of India with an aim to cut the disease transmission chain and end tuberculosis disease in India by $2025 .^{1}$ The programme includes treatment for new and all other tuberculosis (TB) types. Adverse drugs reactions (ADR) are a great burden to national anti-tuberculosis programme. The ADR can affect the compliance negatively, which results therapeutic failure and may indirectly cause MDR-TB. Numerous studies related to ADR profile for various antituberculosis therapy (ATT) has revealed the proportion of ADRs in TB treatment. ${ }^{2,3}$

The literature review in this study cited only few studies which were the studies of the western countries which had different strategies in ADR profile among ATT patients. ${ }^{4,5}$ Moreover, it is expected that ATT therapies may have significant load to patient in the form of cumulative drug toxicities, drug-drug interactions, high pill burden, complicating the treatment outcomes and the history of TB. Pertaining to this view and changes in recent regimens, the present study was done to assess the ADRs in patients receiving ATT.

\section{METHODS}

This prospective, cross-sectional study was conducted during January 2020 to July 2020 after obtaining approval from Institutional Ethical Committee vide no: ECR/1160/Inst/AP/2018/ IEC NRIMC 128). Eligible subjects were recruited from department of pulmonology medicine after taking the consent from all the patients.

New cases of TB attending OPD's on ATT, patients who were on regular follow up presenting with any ADR were included for one-point analysis in current study using 
spontaneous ADR reporting form. All patients reporting ADR were assessed till final outcome of ADR. Patients with therapeutic failure, over-dosage, non-compliance, medication errors, were excluded from the study. Patient of TB with HIV were also excluded.

The ADRs were defined and categorized as per the definition of Edwards and Arsonson. ${ }^{6}$ The suspected ADRs were classified in term of causality using WHOUMC scale and Naranjo scale. ${ }^{7,8}$

\section{Statistical analysis}

Statistical analysis was done using GraphPad prism online software. In the current study the data was expressed in $\mathrm{n}(\%)$, mean and standard deviation (SD).

\section{RESULTS}

During the study period a total of 92 patients presented with ADRs. Ninety-two patients receiving ATT presented with 113 adverse drug events respectively. On comparison, Males were more affected than females. The number of patients in TB was more from the rural areas. DOTS category-1 regimen was mostly associated responsible for ADE in patients (Table 1).

Table 1: Patient characteristics.

\begin{tabular}{|ll|}
\hline Patient characteristics & $\mathbf{N}$ \\
\hline Total period of study (months) & 6 \\
\hline Total no ADRs cases & 92 \\
\hline Total number of ADR events & 113 \\
\hline BMI mean \pm SD & $21.32 \pm 1.8$ \\
\hline Age mean \pm SD & $38.72 \pm 11.6$ \\
\hline $\begin{array}{l}\text { Sex distribution }- \\
\text { male vs female ratio } \\
\text { N }(\%)\end{array}$ & $77(83.69) / 15(16.3)$ \\
\hline DOTS category-I (n) & 92 \\
\hline
\end{tabular}

BMI - body mass index, $\mathrm{N}$ - frequency, $\mathrm{n} \%$ - percentage, SD standard deviation.

Epigastric pain was the most common presentation in TB patients, followed by loss of appetite and vomiting. ADR related to GIT system was followed by nervous system (Figure 1). The next most common system involved was the nervous system comprising of dizziness, anxiety, psychosis and sedation. Myalgias due to pyrazinamide and rifampicin were reported in patients of our study. Deranged LFTs were also seen in our study.

Type A reaction were maximum followed by type C, while B type reactions were least. Most of the ADE's were latent followed by sub-acute onset. Maximum ADR severity events were moderate followed by severe ADRs.

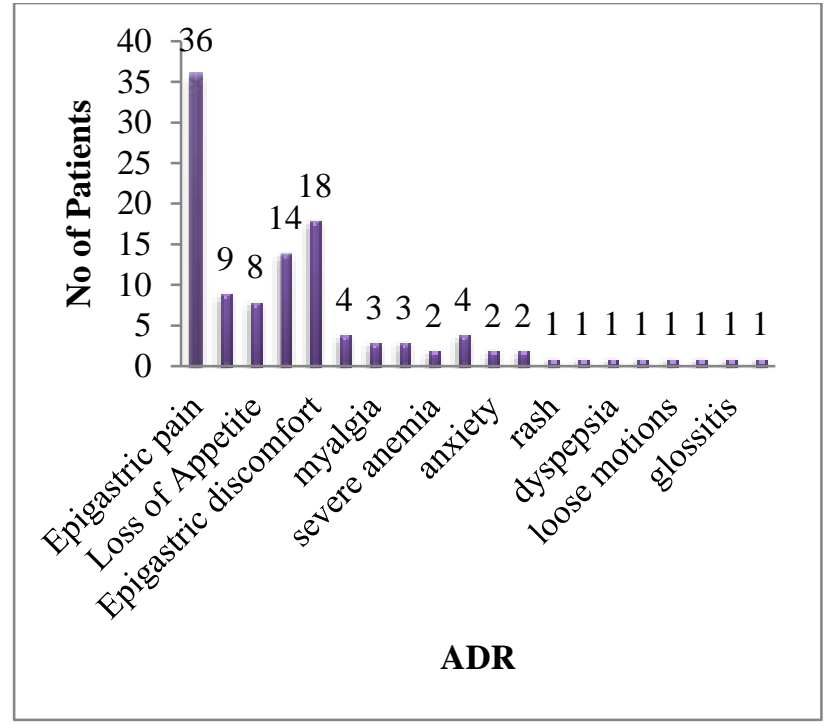

Figure 1: Incidence of ADR in patients of TB treatment.

Table 2: ADR assessment.

\begin{tabular}{|c|c|c|c|}
\hline \multicolumn{2}{|c|}{ ADR characteristics } & $\mathbf{N}$ & $\%$ \\
\hline \multirow{4}{*}{ Severity of ADRS } & Mild & 3 & 3.3 \\
\hline & Moderate & 66 & 71.73 \\
\hline & Severe & 23 & 25 \\
\hline & Fatal & 0 & 0 \\
\hline \multirow{3}{*}{ Mode of onset } & Acute & 9 & 9.78 \\
\hline & Subacute & 16 & 17.4 \\
\hline & Latent & 67 & 72.8 \\
\hline \multirow{6}{*}{ Type of reactions } & A & 80 & 86.9 \\
\hline & $\mathrm{B}$ & 2 & 2.2 \\
\hline & $\mathrm{C}$ & 10 & 10.9 \\
\hline & $\mathrm{D}$ & 0 & 0 \\
\hline & $\mathrm{E}$ & 0 & 0 \\
\hline & Unclassified & 0 & 0 \\
\hline \multirow{4}{*}{$\begin{array}{l}\text { Causality as per } \\
\text { Naranjo's scale }\end{array}$} & Definite & 0 & 0 \\
\hline & Probable & 39 & 42.3 \\
\hline & Possible & 53 & 57.6 \\
\hline & Doubtful & 0 & 0 \\
\hline \multirow{6}{*}{$\begin{array}{l}\text { Causality as per } \\
\text { WHO-UMC } \\
\text { scale }\end{array}$} & Certain & 39 & 42.3 \\
\hline & Probable & 53 & 57.6 \\
\hline & Possible & 0 & 0 \\
\hline & Unlikely & 0 & 0 \\
\hline & Unclassified & 0 & 0 \\
\hline & Unassessible & 0 & 0 \\
\hline \multirow{4}{*}{$\begin{array}{l}\text { Outcome of the } \\
\text { ADRS }\end{array}$} & Recovered & 75 & 81.5 \\
\hline & Recovering & 17 & 18.5 \\
\hline & Continuing & 0 & 0 \\
\hline & Unknown & 0 & 0 \\
\hline \multirow{2}{*}{$\begin{array}{l}\text { Management of } \\
\text { ADRS }\end{array}$} & $\begin{array}{l}\text { Intervention } \\
\text { required }\end{array}$ & 92 & 100 \\
\hline & $\begin{array}{l}\text { No } \\
\text { intervention }\end{array}$ & 0 & 0 \\
\hline
\end{tabular}

$\mathrm{N}$ - frequency, \% - percentage. 
Most of the ADR events did not warrant any change in treatment and $100 \%$ patients were recovered fully in TB (Table 2). As per the Naranjo's probability scale, most of the events were of possible nature and probable. Causality assessment based on WHO-UMC revealed similar trends. Type A reactions were more common. No addition or substitution of the drugs was done for treatment of the ADR. Rest all the parameters pertaining to ADRs were comparable (Table 2).

\section{DISCUSSION}

Analysis of ADRs in patients receiving ATT in this study revealed that the maximum number of patients were of age group of 41-50 years which in accordance to the study of Ramanath et al. ${ }^{9}$ Whereas, Chhetri et al reported a total $29.33 \%$ of ADRs in the age group 21-30 years. ${ }^{10}$ In present study ADR events were more in males in accordance to previous studies. ${ }^{11,12}$

The most common system involved among ATT users was GIT comprising of epigastric pain, vomiting, loss of appetite, followed by gastritis and these results are consistent with Tak et al. ${ }^{13}$ Similar observations were made by Chhetri et al. ${ }^{10}$ Tak et al who also reported CNS to account for $14.28 \%$ of which dizziness comprised of $4.76 \%$ events. ${ }^{13}$ Most likely drugs causing dizziness in present study were isoniazid, rifampicin, and pyrazinamide similar to observations of Ramanath et al. ${ }^{9}$ Similarly, Koju et al and Ramanath et al have also reported common involvement of musculoskeletal system in form of myalgia. ${ }^{9,11}$ Dermatological system comprising of rash and glossitis was seen in agreement to the findings of Qayyum et al who observed $7.1 \%$ dermatological involvement. ${ }^{2}$ However, the highest percentage of dermatological involvement $27.34 \%$ was reported by Ramanath et al unlike our study observations. ${ }^{9}$ Ali observed that transient elevations of serum hepatocellular enzymes alanine amino transferase, asparate amino transferase, in approximately $10 \%$ of patients who received a standard combination chemotherapy. ${ }^{14} \mathrm{~A}$ significant increase in the total bilirubin, bilirubin direct, AST, ALT, alkaline phosphatase has been reported by Koju et al. ${ }^{11}$

ADR events experienced by TB patients were predominantly latent in nature. Tak et al in their study reported that most of the ADRs $(33.33 \%)$ to be latent in nature. ${ }^{13}$ Maximum ADR events in our study were of moderate severity like the findings of Ramanath et al. ${ }^{9}$ Majority of the ADRs reported by Chhetri et al were "possible" as per Naranjo algorithm which is in accordance to our reports. ${ }^{10}$

Present study reported a recovery in maximum patients with ADRs. Among these majority of ADR events were self-limiting and required no discontinuation of the ATT regimen. In a study by Chhetri et al, majority of the reported ADRs (93.33\%) were mild and did not need modification of treatment like our study. ${ }^{10}$ Similarly, Tak et al has reported full recovery in majority of the patients without any complications and mortality. ${ }^{13}$ This probably may be due to cumulative drug toxicities, drug-drug interactions, complexity of regimens, high pill burden which however remain to be validated in future research. Moreover, the current study does not represent the true volume of the problem due to spontaneous reporting of ADR. Type A reactions were more common in TB group there suggesting that majority of such reaction could have been prevented. Whereas Type B \& $\mathrm{C}$ reaction suggests a strong need to initiate and extend role of pharmacogenomics in PV. The study had some limitations as no attempt was made to establish any correlations with any of the clinical parameters, low number of study population. Thus, outcome of current study stresses upon collaborated activities of NTEP and pharmacovigilance programme of India to enhance drug safety.

\section{CONCLUSION}

The study concludes that the incidence of ADRs in treatment of tuberculosis exist along with maximum percent of efficacy.

Funding: No funding sources

Conflict of interest: None declared

Ethical approval: The study was approved by the Institutional Ethics Committee

\section{REFERENCES}

1. Central TB Division, Ministry of Health and Family Welfare, Government of India. Training modules (14) for programme managers and medical officers. Central TB Division, Ministry of Health and Family Welfare, Government of India. June 2020.

2. Qayyum S, Ahmed I, Baig S, Rizvi N. Adverse events in the treatment of multi-drug resistant tuberculosis. ERS. 2011;4402.

3. Kurniawati F, Sulaiman SAS, Gillani SW. Adverse Drug Reactions of Primary Antituberculosis Drugs Among Tuberculosis Patients treated in Chest Clinic. Int J Pharm Life Sci. 2012;3(1):13312-8.

4. Kwara A, Flanigan TP, Carter EJ. Highly active antiretroviral therapy (HAART) in adults with tuberculosis: current status. Int J Tuberc Lung Dis. 2005;9(3):248-57.

5. Breen RAM, Miller RF, Gorsuch T, Smith CJ. Adverse events and treatment interruption in tuberculosis patients with and without HIV coinfection. Thorax. 2006;61:791-4.

6. Edwards IR, Arsonson JK. Adverse drug reactions: Definitions, diagnosis and management. Lancet. 2000;356:1255-59.

7. Meyboom RHB, Royer RJ. Causality Classification in Pharmacovigilance Centres in the European Community. Pharmacoepidemiology Drug Safety. 1992;1:87-97.

8. Naranjo CA, Busto U, Sellers EM, Sandor P, Ruiz I, Roberts EA, et al. A method for estimating the 
probability of adverse drug reactions. Clin Pharmacol Ther. 1981;30:239-45.

9. Ramanath KV, Ramesh S. A Study on Assessment of Adverse Drug Reaction in Tuberculosis Patients. AM J Pharm Tech Res. 2012;2(2):14-18.

10. Chhetri AK, Saha A, Verma SC, Palaian S, Mishra P, Shankar PR. Study of adv drug reaction caused by First line anti-tubercular drug used in directly observed treatment, Short Cause (DOTS) therapy in Western Nepal. Pokhara Pak Med Assoc. 2008;58(10):531-6.

11. Koju D, Rao BS, Shrestha B, Shakya R, Makaju R. Occurrence of side effects of Anti Tuberculosis Drug in urban Nepalese population under DOTS treatment. Kathmandu J Sci Engineering Technol. 2005;1(1):18.

12. Venkatapraveen A, Rampure MV, Patil N, Hinchageri SS, Lakshmi DP. Assessment of clinical pharmacist intervention to improve compliance and health care outcome of tuberculosis patients. Der Pharmacia Lettre. 2012;4(3):931-37.

13. Tak DK, Acharya LD, Gowrinath K, Padma RGM, Subish P. Safety evaluation of antitubercular therapy under revised national Tuberculosis Control Progpamme in India. J Clin Diagnostic Res. 2009;3:1395-401.

14. Ali J. Hepatotoxic effects of tuberculosis therapy. A practical approach to tricky management problem. Postgrad Med. 1996;99:217-31.

Cite this article as: Krishnakanth $\mathrm{K}$, Jagadeesh A, Swetha TD. Evaluation of Adverse Drug Reactions of Anti-Tubercular drugs in the treatment of tuberculosis in tertiary care hospital. Int J Basic Clin Pharmacol 2020;9:1430-3. 